\title{
Classification of microdefects in semiconducting silicon
}

\author{
V.I. Talanin, I.E. Talanin* \\ Zaporozhye Institute of State \& Municipal Government, 70B, Zhukovskii str., 69002 Zaporozhye, \\ E-mail:V.I.Talanin@mail.ru \\ *Zaporozhye State Engineering Academy, 226, pr. Lenin, 69006 Zaporozhye, Fax: +380 (612) 601498
}

\begin{abstract}
On the basis of experimental analysis (preferential etching, transmission electron microscopy) of the dislocation-free silicon single crystals grown by floating-zone method (FZ-Si) and Czochralski method (Cz-Si), a classification of grown-in microdefects was compiled. The suggested classification is founded on the heterogeneous formation mechanism of grown-in microdefects, which was justified earlier by us. The suggested classification is valid for crystals of either small or large diameter.
\end{abstract}

Keywords: microdefects, silicon, interstitial-type, vacancy-type.

Paper received 26.09.03; accepted for publication 11.12.03.

\section{Introduction}

Down-scaling of semiconductor devices used in electronic equipment and consequent adoption of nano-sized structures both draw an especial attention to the fact that few imperfections, or even a single one, might cause a semiconductor device to fail. In semiconductor silicon this type of imperfections are so-called microdefects. At present the term microdefects is taken to involve any local disturbances of the lattice periodic behaviour measuring from several tens of angstroms to several micrometers that is a transient class of imperfections, i.e. from the point defects to the line ones. Microdefects can be either aggregates of point defects (intrinsic and impurity defects) or precipitates of micron or submicron sizes. In essence, they are decomposition products of the corresponding oversaturated solid solutions. Such oversaturated solid solutions are formed by the impurity defects (dopant or background impurities) and by the intrinsic point defects (vacancies and self-interstitials). Decomposition can occur either directly in the process of the silicon crystal growth at the stage of cooling or during the further thermal processing, and also as a result of some other external agents influencing the crystal.

It is necessary to take into account that the microdefect structure of the initial silicon single crystal directly affects the process, in which the oversaturated solid solutions of intrinsic point defects and impurities are decomposed as a result of the external influences and further technological treatments. Therefore, a direct compari- son between the microdefects of the silicon single crystals and the microdefects of the thermally processed silicon and structures built on its basis is impossible. As a result, there is a need in distinct division of the term "microdefects" into the grown-in microdefects and the secondary microdefects.

\section{Grown-in microdefects in semiconductor silicon}

Historically the classification of the grown-in microdefects in FZ-Si was based on adoption of preferential etching and X-ray topography with decoration. The large etching pits of smaller concentration were called Amicrodefects, while the small etching pits of greater concentration were called B-microdefects. Under preferential etching of the transverse sections of the crystal a pattern of pit distribution transpires in the form of a discontinuous spiral (swirl distribution).

When crystals are grown at a high rates, a new type of microdefects was observed as uniform distribution and could be identified as mat regions after preferential etching and decoration [3]. These defects were classified as $C$ - or $D$-microdefects depending on the their macrodistribution images. Both types were visualized as the regions with uniform defect distribution of high density and, according to the authors of the Ref. [3], differed from each other by distribution geometry. The uniform $D$ microdefects distribution is focused in the form of a "channel" in the central part of the crystal. $C$-microdefects were 


\section{V.I.Talanin, I.E.Talanin: The microdefects classification in semiconducting silicon}

observed as rings or circles of irregular shape, located at the most extensively cooled parts of the crystal.

In Cz-Si $A$-, $B$ - and D-microdefects, identical to defects in FZ-Si $[4,5]$, were also observed using preferential etching technique. On the basis of X-ray topography results coupled with copper decoration, researchers in [6] made an assumption that the $D$-microdefects in $\mathrm{Cz}-\mathrm{Si}$ are vacancy-type. From this assumption, V.V. Voronkov developed a theoretical model of the formation mechanism of microdefects in $\mathrm{Cz}-\mathrm{Si}$, which was accepted as common model and recently applied to FZ-Si $[7,8]$. Voronkov's common model is based on the following: 1) there is a recombination between intrinsic point defects at temperatures close to melting point; 2) there are areas with only interstitial-type ( $A$ - and $B$-microdefects) or vacancy-type microdefects ( $D$-microdefects); 3 ) there is a critical parameter $C_{c r i t}=V / G$ (where $V$ is a crystal growth rate; $G$ is an axial temperature gradient). When $V / G<C_{c r i t}$, self-interstitials dominate in the crystal (interstitial-type crystal growth) and when $V / G>C_{\text {crit }}$, vacancies prevail in the crystal (vacancy-type crystal growth).

The drawbacks of the existing classification (and the drawbacks of the theoretical models based upon it) are in that it does not provide any information about the sign of lattice imperfection, which depends on the microdefect type. The sign of defect-induced lattice imperfection (often defined as the microdefect physical nature) bears an implicit information of the defect chemical composition. At the same time it allows to determine the mechanisms, through which the grown-in microdefects form and transform. It was exactly the absence of this parameter that caused confusion in identification and classification of $D$-microdefects in FZ-Si and Cz-Si.

\section{Experimental}

We have conducted a series of experiments with the FZ$\mathrm{Si}$ and $\mathrm{Cz}-\mathrm{Si}$ using preferential etching and TEM. The silicon crystals of $30 \mathrm{~mm}(\mathrm{FZ}-\mathrm{Si})$ and $50 \mathrm{~mm}(\mathrm{Cz}-\mathrm{Si})$ in diameter were studied. These diameters were chosen because all the known types of the grown-in microdefects are formed in crystals of such diameters when thermal conditions of crystal growth vary. The larger diameter of a crystal requires change in growth thermal conditions that significantly constricts the range of observed microdefects.

FZ-Si crystals were not doped, oxygen and carbon concentrations were less than $5 \cdot 10^{15} \mathrm{~cm}^{-3}$, the number of passes varied from 2 to $10, \rho=(2 \ldots 4) \cdot 10^{3} \mathrm{~W} \cdot \mathrm{cm} . \mathrm{Cz}-\mathrm{Si} \mathrm{n}-$ type crystals were with $\rho=10 \ldots 50 \mathrm{~W} \cdot \mathrm{cm}$, oxygen concentration $\sim(4 \ldots 7) \cdot 10^{17} \mathrm{~cm}^{-3}$, carbon $\sim(5 \ldots 7) \cdot 10^{16} \mathrm{~cm}^{-3}$. The crystals were grown at constant growth rates ranging from 1 to $9 \mathrm{~mm} / \mathrm{min}$ (for FZ-Si) and 0.5 to $3 \mathrm{~mm} / \mathrm{min}$ (for $\mathrm{Cz}-\mathrm{Si}$ ). Several crystals were obtained under specially conditions growth rate change.

Sirtl etch was used to identify microdefects of different types and their distribution images. The inside-out- side contrast method [9], black-white contrast method [10] and defocused dark-field image method (2.5D) [11] were used to determine the sign of lattice imperfection. Electron microscope with $100 \mathrm{kV}$ acceleration voltage was employed that excludes radiation defect infusion [12].

\section{Results}

Large number of crystals studied (over 60 FZ-Si ingots and over $15 \mathrm{Cz}-\mathrm{Si}$ ingots), which were obtained under various thermal growth conditions enabled us to make a schematic representation of the microdefect distribution in FZ-Si and $\mathrm{Cz}-\mathrm{Si}$ under the changing crystal growth rate (Fig. 1).

As one can see in Fig. 1, with gradual increase of growth rate, one type of microdefects in FZ-Si crystals is replaced progressively with the other type. $A$-microdefect large swirls are replaced with smaller swirls of $B$-microdefects. After the rate $V_{r}$ reaches a certain value (at which the remelting phenomenon is suppressed) $B$-microdefects are replaced with uniform $D$-microdefect distribution. For FZ-Si we determined the adjusted value of rate $V_{r} \sim$ $\sim 4.5 \mathrm{~mm} / \mathrm{min}$. Our study results showed that above a certain critical growth rate $V_{\text {crit }}$ the vacancy-type microdefects begin to occur in crystals, while before $V_{\text {crit }}$ only interstitial-type microdefects could be detected. If $V>V_{r}$, interstitial $D$-microdefects usually converge in a channel, which afterwards at $V$ i $V_{\text {crit }}$ begins to diverge towards the periphery of the crystal. If the crystal growth rate continues to rise, the ring size diminishes (in plane (111)), and at $V \sim 8 \ldots 9 \mathrm{~mm} / \mathrm{min}$ the ring of interstitialtype microdefects disappears, while vacancy-type and interstitial-type microdefects coexist within the whole crystal body in approximately equal concentrations. Thus, as the crystal growth rate decreases, the interstitial-type microdefects are continuously transformed. Above $V_{\text {crit }}=$ $=6 . .6 .5 \mathrm{~mm} / \mathrm{min}$ vacancy-type microdefects occur and their concentration continues to increase up to $V \sim 9 \mathrm{~mm} / \mathrm{min}$, when both concentrations of vacancy-type and interstitial-type microdefects become approximately equal.

As for $\mathrm{Cz}-\mathrm{Si} \varnothing 50$ crystals growing, the growth rates are moved to smaller values. The occurrence of uniform defect distribution is typical for the values: $1.5 \mathrm{~mm} / \mathrm{min}<$ $<V<2 \mathrm{~mm} / \mathrm{min}$. Though, according to Voronkov's model, interstitial-type $A$ - and $B$-swirls should occur only at $V<V_{\text {crit } 1}$, where $V_{\text {crit } 1}$ is defined as a theoretical value characterised by the vacancy-type microdefects occurrence and the interstitial-type microdefects vanish [7, 8]. According to our estimation for crystals $\varnothing 50 \mathrm{~mm}$ this rate will be between 0.8 and $1.2 \mathrm{~mm} / \mathrm{min}$.

We conducted TEM-research for microdefects of different types in FZ-Si and Cz-Si to determine their origin. Below is a summary of the major results obtained from the experiments.

1) For FZ-Si [13-16]:

- $A$-microdefects constitute interstitial-type dislocation loops with sizes of 1 to $50 \mu \mathrm{m}$ and the Burgers vector $\bar{b}=1 / 2$ [110] lying in planes $\{111\}$ and $\{110\}$; 


\section{V.I.Talanin, I.E.Talanin: The microdefects classification in semiconducting silicon}
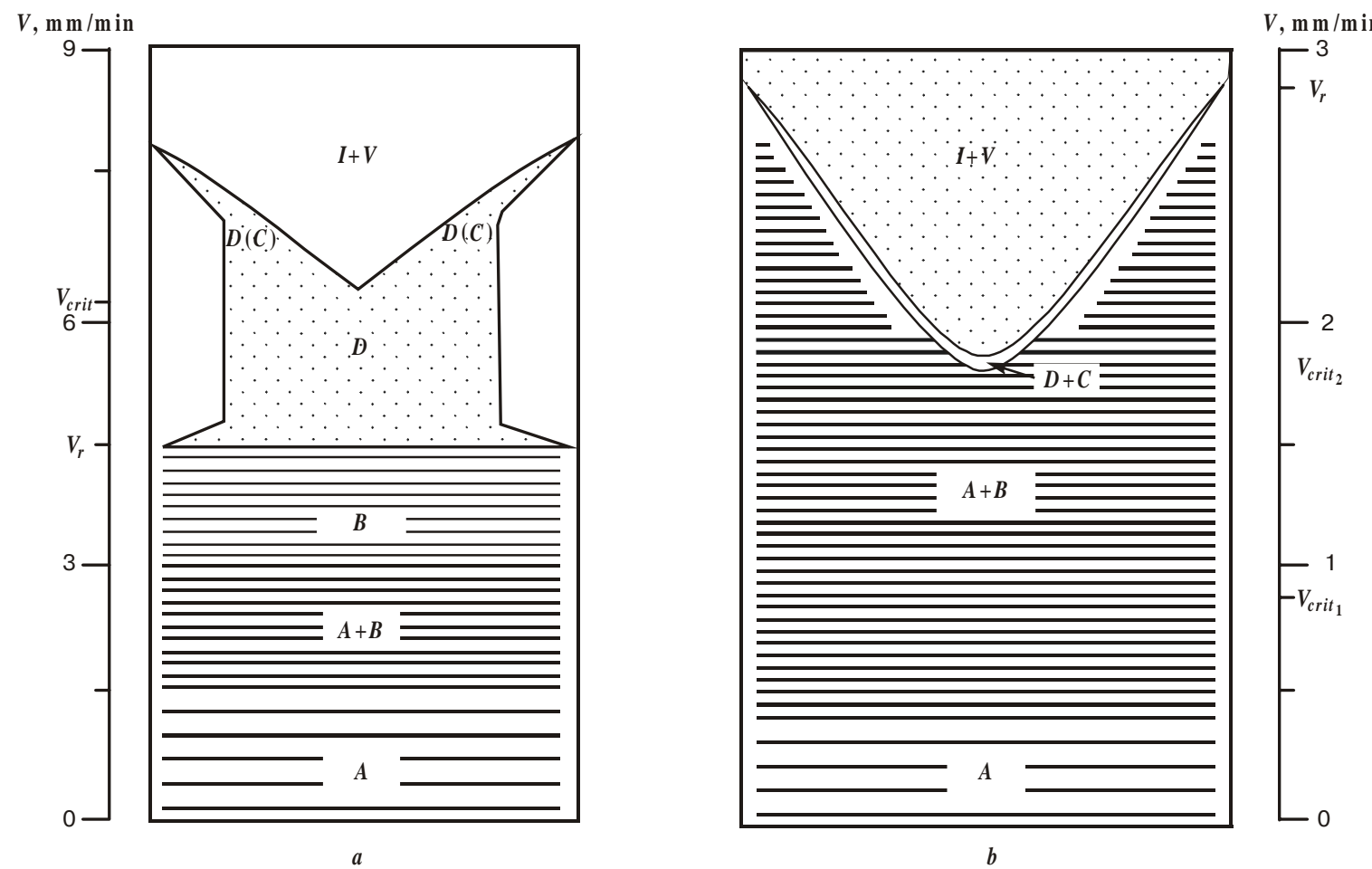

Fig. 1. Schematic formation and transformation mechanism of microdefects in silicon single crystals, plane (112): $a$ - FZ-Si crystal $\varnothing 30 \mathrm{~mm} ; b-\mathrm{Cz}-\mathrm{Si}$ crystal $\varnothing 50 \mathrm{~mm}$;

$V_{\text {crit }}, V_{\text {crit } 2}$ - crystal growth rates determined experimentally, at which the vacancy-type microdefects occur (vanish), $\mathrm{mm} / \mathrm{min}$; $V_{r}$ - crystal growth rate, at which the remelting phenomenon is suppressed;

$V_{\text {crit } 1}$ - crystal growth rate calculated theoretically, at which vacancy-type microdefects occur while the interstitial-type defects vanish (according to Voronkov's model), $\mathrm{mm} / \mathrm{min}$.

- $B$-microdefects constitute interstitial-type aggregates of point defects with sizes of 20 to $\varnothing 50 \mathrm{~nm}$, some of them lye in $\{100\}$ and $\{111\}$;

- $D$-microdefects constitute interstitial-type aggregates of point defects with size of 4 to $10 \mathrm{~nm}$; they may be considered as uniform B-microdefect distribution;

- $C$-microdefects are entirely identical to $D$-microdefects as far as contrast of TEM images and the sign of lattice imperfection is concerned; they only differ by the distribution geometry. Therefore, there is no need to separate them into a distinct type of defects;

- at high growth rates (exceeding $6 \mathrm{~mm} / \mathrm{min}$ ), the interstitial-type microdefects occur simultaneously with the vacancy-type microdefects and are localised in the same areas $-(I+V)$-defects.

- the transformation of interstitial-type microdefects has the following scheme: $D$-microdefects $\rightarrow B$-microdefects $\rightarrow A$-microdefects.

- background oxygen and carbon impurities directly participate in the defect formation mechanism as nucleation centers and in further growth as well as transformation of the microdefects.

2) For $\mathrm{Cz}-\mathrm{Si}[17,18]$ :

- microdefects in the area of the ring are interstitialtype aggregates of point defects with sizes of 4 to $12 \mathrm{~nm}$;

- inside the ring there are defects of interstitial and vacancy types $-(I+V)$-defects with sizes of 4 to $12 \mathrm{~nm}$;
- there is no difference between the microdefects in the ring area and $D$-microdefects in FZ-Si with regard to their sizes, sign of lattice imperfection and macrodistribution geometry;

- the transformation of interstitial microdefects follows this pattern: $D$-microdefects $\rightarrow B$-microdefects $\rightarrow$ $A$-microdefects.

In addition, it was recently reported that, as per TEM observations, defects outside the ring constitute clusters of interstitial-type point defects and interstitial-type dislocation loops $[19,20]$. It was shown earlier that defects occurred at $V<V_{\text {crit } 2}$ (see Fig. 1) are of the interstitial type [21-23].

Obtained experimental results unambiguously prove that the defect formation mechanism in FZ-Si is identical to that in $\mathrm{Cz}-\mathrm{Si}$. With due regard to thermal growth conditions and the sign of lattice imperfection (microdefects physical nature), we can classify the grown-in microdefects in the semiconductor silicon as follows (Tables 1,2).

Data comparison in Fig. 1 and in Tables 1 and 2 makes it clear that $D$-microdefects are not detected in $\mathrm{Cz}-\mathrm{Si}$ in channel distribution. This may be concerned with the following. The change in thermal growth conditions causes the suppression of remelting phenomenon (this phenomenon is responsible for striated distribution of $A$ - and $B$-microdefects) that occurs in FZ-Si in interstitial-type growth and in Cz-Si in vacancy-interstitial-type 
V.I.Talanin, I.E.Talanin: The microdefects classification in semiconducting silicon

Table 1. Classification of microdefects in FZ-Si $(\varnothing 30 \mathrm{~mm})$

\begin{tabular}{|c|c|c|c|c|c|}
\hline Type & Physical nature & Size, $n m$ & $V, \mathrm{~mm} / \mathrm{min}$ & $\begin{array}{l}\text { Distribution } \\
\text { in plane (112) }\end{array}$ & $N, \mathrm{~cm}^{-3}$ \\
\hline$A$ & interstitial-type dislocation loops & up to 50000 & $1 \ldots 3.5$ & striated & $\sim 10^{6}$ \\
\hline$B$ & $\begin{array}{l}\text { interstitial-type aggregates } \\
\text { of point defects }\end{array}$ & $20 \ldots 50$ & $\leq 4.5$ & striated & $\sim 10^{7}$ \\
\hline$D$ & $\begin{array}{l}\text { interstitial-type aggregates } \\
\text { of point defects }\end{array}$ & $4 \ldots 10$ & $>4.5$ & uniform & $\sim 10^{13}$ \\
\hline$D(C)$ & $\begin{array}{l}\text { interstitial-type aggregates } \\
\text { of point defects }\end{array}$ & $4 \ldots 10$ & $>4.5$ & $\begin{array}{l}\text { uniform, ring-like } \\
\text { in plane (111) }\end{array}$ & $\sim 10^{13}$ \\
\hline$I+V$ & interstitial + vacancy-types & $4 \ldots 12$ & $>6.0$ & uniform & $\sim 10^{13}$ \\
\hline
\end{tabular}

Table 2. Classification of microdefects in Cz-Si $(\varnothing 50 \mathrm{~mm})$

\begin{tabular}{cccccc}
\hline \hline Type & Physical nature & Size,nm & $V, \mathrm{~mm} / \mathrm{min}$ & $\begin{array}{c}\text { Distribution } \\
\text { in plane }(112)\end{array}$ & $N, \mathrm{~cm}^{-3}$ \\
\hline$A$ & interstitial-type dislocation loops & up to 50000 & $\leq 2.5$ & striated & $\sim 10^{6}$ \\
\hline$B$ & $\begin{array}{c}\text { interstitial-type aggregates } \\
\text { of point defects }\end{array}$ & $20 \ldots 50$ & $\begin{array}{c}\leq 2.5 \\
\text { and }>0.5\end{array}$ & striated \\
\hline$D(C)$ & $\begin{array}{c}\text { interstitial-type aggregates } \\
\text { of point defects }\end{array}$ & $4 \ldots 12$ & $1.8 . .2 .7$ & $\begin{array}{c}\text { uniform, ring-like } \\
\text { in plane }(111)\end{array}$ & $\sim 10^{13}$ \\
\hline$I+V$ & interstitial + vacancy-types & $4 \ldots 12$ & $>2.0$ & uniform & $\sim 10^{13}$ \\
\hline \hline
\end{tabular}

growth. Furthermore, oxygen and carbon are present in $\mathrm{Cz}-\mathrm{Si}$ crystal in much greater concentrations than in FZ$\mathrm{Si}$. Therefore, oxygen precipitation is in close interrelation with the $\mathrm{Cz}-\mathrm{Si}$ defect structure and leads to interstitial-type dislocation loops occurrence outside the $D(C)$ microdefects ring.

Based on the experimental results obtained, we can draw the following conclusions:

1. The boundary of the vacancy-type microdefects occurrence (vanish) shall be defined if the real thermal growth conditions (axial and radial temperature gradients, crystal growth and cooling rates, diameter of the crystal and the growth method) are concerned. From this, $V_{\text {critmin }}=V_{\text {crit } 2}$ for $\mathrm{Cz}-\mathrm{Si}$.

2. In crystals FZ-Si and Cz-Si, there is no area where only vacancy-type growth occurs. Hence, the type of growth characterising by vacancy-type microdefects should be called as vacancy-interstitial-type of crystal growth.

3. The "defect-free" area between the interstitial and vacancy-interstitial regions of crystal growth was found to contain defects of interstitial-type [16]. This was clarified using TEM; methods of preferential etching or Xray topography do not reveal these defects.

\section{Discussion}

From our viewpoint, the experiments with high pure FZSi are of especial importance. These were the experiments that allowed us to suggest the heterogeneous formation mechanism of grown-in microdefects [16]. Its basic principles can be outlined as follows:

- recombination of intrinsic point defects at about crystallization temperature is hindered because of recombination barrier;

- background impurities of oxygen and carbon participate in the process of defect formation as nucleation centers, and consequently participate in the processes of further growth and transformation of grown-in microdefects;

- cooling-induced decomposition of the oversaturated solid solution of point defects in silicon follows two mechanisms: vacancy-type and interstitial-type.

For vacancy-type mechanism:

1) $n \mathrm{O}_{i}+V_{\mathrm{Si}} \rightarrow n\left(V \mathrm{O}_{2}\right) \rightarrow$ vacancy-type microdefects.

2) $n\left(V \mathrm{O}_{2}\right)+\mathrm{O}_{i}+\ldots+n \mathrm{O}_{i} \rightarrow n\left[\left(V_{n} \mathrm{O}_{n}\right)+I_{\mathrm{Si}}\right] \rightarrow D-$ microdefects.

For interstitial-type mechanism:

1) $C_{s}+I_{\mathrm{Si}} \rightarrow\left(C_{s} I_{\mathrm{Si}}\right) \rightarrow D$-microdefects.

2) $\left(C_{s} I_{\mathrm{Si}}\right)+\mathrm{O}_{i} \rightarrow n\left[\left(C_{s} I_{\mathrm{Si}}\right)+\mathrm{O}_{i}\right] \rightarrow B$-microdefects.

3) $B$-microdefects $+I_{\mathrm{Si}} \rightarrow A$-microdefects.

We consider the suggested mechanism as the "core" of defects formation mechanism. To change the "core" (i.e., to control decomposition of the oversaturated solid solutions of point defects) is possible as follows:

- to vary thermal growth conditions (growth rate, temperature gradients at the phase boundary, cooling rate); 


\section{V.I.Talanin, I.E.Talanin: The microdefects classification in semiconducting silicon}

- to adjust the condition of the intrinsic point defects ensemble in the crystal by employing various external factors (doping, radiation, etc.);

- to subject the grown single crystals to different kinds of thermal processing.

Comparing FZ-Si crystals with $\mathrm{Cz}-\mathrm{Si}$ crystals, one can see the changes in distribution images of grown-in microdefects. It is related to both the change in thermal growth conditions of the crystal and a much greater concentration of carbon and oxygen impurities (with the latter being especially important). Vacancy microdefects in $\mathrm{Cz}-\mathrm{Si}$ crystals have black-white contrast on TEM images, since the field of imperfection exceeds the defect size [17, 18]. Therefore, one cannot define for certain whether these are oxygen-vacancy aggregates or voids. However, it has been shown that oxygen-vacancy condensation in the small-diameter Cz-Si crystals begins before pure vacancy condensation [24]. Thus, the vacancy-type microdefects observed by us constitute the oxygen-vacancy agglomerates leading to the precipitation of oxygen.

An increase in diameter of silicon single crystals leads to a significant change in the thermal growth conditions. Accordingly, the vacancy condensation becomes more important when the silicon ingot is cooled. In the past ten years different researchers observed new grown-in microdefects in vacancy-interstitial-type growth in largediameter silicon crystals that further cause the degradation of semiconductor devices [25, 26]. Depending on the observation technique they were called as: FP-defects (flow pattern defects), COP-defects (crystal-originated particles) and LST-defects (light-scattering tomography defects) [27].

With the use of TEM the shape and size of LST-defects were determined $(100 \ldots 300 \mathrm{~nm})$ [28, 29]. Although TEM observation fails to determine the sign of the defect-induced lattice imperfection, on the basis of a smaller content of oxygen in the center of the defect as compared to the periphery, was assumed that LST-defects constitute microvoids, i.e. they are the vacancy-type ones. This enabled a group of researchers to interpret all the defect types identified by different techniques as one type of defects identical to $D$-microdefects in FZ-Si and $\mathrm{Cz}-\mathrm{Si}$ formed as a result of homogenous nucleation [8, 25-32]. Another group of authors, on the grounds of their experimental results, adhere to the opposite viewpoint [21-23, $33,34]$. In [35] an assumption was made that the formation mechanism of grown-in microdefects is mostly influenced by the joint agglomeration of self-interstitials and carbon atoms (found in LST-defects [36]) instead of oxygen precipitation. Similar results were obtained in [37], where it was shown that OSF-rings are formed as per heterogeneous mechanism under simultaneous oxygen precipitation and agglomeration of silicon self-interstitials with atoms of "non-oxygen impurity". Of significant interest are the results presented in [38]. Here the authors have used the X-ray diffuse scattering method to detect both interstitial-type and vacancy-type defects coexisting in $\mathrm{Cz}-\mathrm{Si}$ vacancy-interstitial-type growth.
From the experimental results analysis of grown-in microdefects in Cz-Si crystals, 150 to $300 \mathrm{~mm}$ in diameter, we come to the conclusion that crystals grown under vacancy-interstitial-type growth contain defects of both vacancy and interstitial types. Increasing the crystal diameter leads to an abrupt change of thermal growth conditions as compared to $\mathrm{Cz}-\mathrm{Si}$ crystals of $50 \mathrm{~mm}$ in diameter. Adjusting thermal growth conditions as well as crystal doping allow to control the formation mechanism and growth of vacancy-type and interstitial-type defects under conditions of vacancy-interstitial-type growth. This results in the defect size and shape change and give an advantage to vacancy agglomeration over oxygen-vacancy agglomeration. However, the basic principles (i.e. "core") of the heterogeneous mechanism suggested for the grown-in microdefects formation in FZ-Si and Cz-Si remain unchanged. Within the classification suggested the new defects of vacancy-interstitial-type growth in large-diameter crystals are referred to grown-in $(I+V)$ defects.

This inference is supported by the TEM results for vacancy-type microdefects, which researchers termed as "microvoids" [28, 29, 34, 39]. After short-time high-temperature processing microvoids become smaller in size and their images show dark spots of oxygen precipitates (secondary microdefects). It means that the octahedral microvoids are formed owing to vacancies agglomeration in the course of consequent as-grown crystal cooling. They occur on the oxygen-vacancy agglomerates that are formed by first. The joint condensation of oxygen and vacancies (i.e. formation of $\mathrm{SiO}_{2}$ particles) causes the absorption of vacancies, which supposed to diminish the energy of the oversaturated vacancy solution. However, this channel of vacancies absorption does not gain prevalence in large-diameter crystals. Under such conditions a pure vacancy precipitation prevails, which leads to the octahedral microvoids formation. We presume that this defect is not a void of a pure form, but rather a very loose, amorphous area near the oxygen-vacancy precipitate. Further thermal processing of the crystal supports our assumption. It needs to be emphasised that there are experimental results evidencing that such agglomeration of the vacancies is also possible on carbon-interstitial agglomerates when large-diameter crystals are cooled $[36,40]$.

\section{Conclusions}

The distribution images of the grown-in microdefects as a function of the growth rate of small-diameter FZ-Si and $\mathrm{Cz}-\mathrm{Si}$ crystals, coupled with the sign of the microdefect-induced lattice imperfection enable us to compile a common classification of the grown-in microdefects. This classification also includes the new microdefects that occur in large-diameter crystals. According to heterogeneous formation mechanism of grown-in microdefects, the oxygen-vacancy agglomerates and the carbon-interstitial agglomerates are the driving factors of the formation mechanism of microdefects. Controlling the decom- 


\section{V.I.Talanin, I.E.Talanin: The microdefects classification in semiconducting silicon}

position process of the oversaturated solid solution of point defects leads to that the defects of different structure are formed in the interstitial-type and vacancy-interstitial-type crystal growth.

\section{References}

1. A.J.R. de Kock // Philips Res. Rept. Suppl. 1973. № 1. P. 1.

2. A.J.R. de Kock, P.J. Roksnoer, P.G.T. Boonen // J. Crystal Growth, 1974, 22(4), P. 311.

3. N.V. Veselovskaya, E.G. Sheikhet, K.N. Neimark, E.S. Falkevich // In: Rost i legirovanie polyprovodnikovych kristallov i plenok. Novosibirsk: Nauka, 1977, V. 2, P. 284.

4. A.J.R. de Kock, W.T. Stacy, W.M. van de Wijgert // Appl. Phys. Lett, 1979, 34(9), P. 611.

5. A.J.R. de Kock, W.M. van de Wijgert // J. Crystal Growth. 1980, 49(4), P. 718.

6. P.J. Roksnoer, M.M.B. van den Boom // J. Crystal Growth. 1981, 53(3), P. 563.

7. V.V. Voronkov // J. Crystal Growth. 1982, 59(3), P. 625.

8. V.V. Voronkov, R. Falster // J. Crystal Growth, 1998, 194(1), P. 76.

9. H. Foll, M. Wilkens // Phys. Stat. Sol. (a), 1975, 31(4), P. 519.

10. M.F. Ashby, L.M. Brown // Phil. Mag., 1963, 8(12), P. 1649.

11. J.B. Mitchell, W.L. Bell // Acta Met., 1976. 24(2), P. 147.

12. M. Pasemann, P. Werner // Phys. Stat. Sol. (a), 1980. 58(1), P. K1.

13. A.A. Sitnikova, L.M. Sorokin, I.E. Talanin et al. // Phys. Stat. Sol. (a), 1984, 81(2), P. 433.

14. A.A. Sitnikova, L.M. Sorokin, I.E. Talanin et al. // Fiz. tverd. tela, 1986. 28(6), P. 1829

15. V.I. Talanin, I.E. Talanin, D.I. Levinson // Semic. Sci. \& Technol., 2002, 17(2), P. 101.

16. V.I. Talanin, I.E. Talanin, D.I. Levinson // Cryst. Res. \& Technol., 2002, 37(9), P. 983

17. V.I. Talanin, I.E. Talanin, D.I. Levinson // In: Vusokochistue metallicheskie i polyprovodnikovue materialu. Charkov: NNC, 2002. P. 74

18. V.I. Talanin, I.E. Talanin // Phys. Stat. Sol. (a), 200(2), p. 297 (2003).
19. J. Furukawa, H. Tanaka, Y. Nakada et al. // J. Crystal Growth. 2000, 210(1), P. 26.

20. M. Okue, M. Nishimoto // J. Crystal Growth, 2002, 237(10), P. 1651.

21. S. Sadamitsu, S. Umeno, Y. Koike et al. // Jpn. J. Appl. Phys., 1993, 32(9), P. 3675.

22. N. Nango, S. Iida, T. Ogawa // J. Appl. Phys., 1999, 86(11), P. 6000 .

23. S. Iida, Y. Aoki, K. Okitsu et al. // Jpn. J. Appl. Phys., 1998, 37(1), P. 241.

24. V.V. Voronkov, M.G. Milvidskii // Kristallographia, 1988, 33(2), P. 471.

25. W.P. Lee, W.S. Seow, H.K. Yow, T.Y. Tou // Jpn. J. Appl. Phys., 2001, 40(1), P. 18.

26. K. Harada, H. Tanaka, T. Watanabe, H. Furuya // Jpn. J. Appl. Phys., 1998, 37(6), P. 3194.

27. S. Umeno, Y. Yanase, M. Hourai, M. Sano // Jpn J. Appl. Phys., 1999, 38(10), P. 5725.

28. M. Kato, T. Yoshida, Y. Ikeda, Y. Kitagawa // Jpn. J. Appl. Phys., 1996, 35(11), P. 5597.

29. M. Nishimura, S. Yoshino, H. Motoura et al. // J. Electrochem. Soc., 1996, 143(10) P. L243.

30. W. von Ammon, E. Dornberger, P.O. Hansson // J. Crystal Growth, 1999, 198(1), P. 390.

31. S. Umeno, M. Okui, M. Hourai, M. Sano, H. Tsuya // Jpn. J. Appl. Phys., 1997, 36(5), P. L591.

32. V.V. Voronkov, R. Falster // J. Crystal Growth, 1999, 198(1), P. 399.

33. H. Rauh, D. Sieger, A. Wright // In: Defect Control in Semiconductors. Amsterdam, 1990. Vol. 2. P. 1541.

34. M. Itsumi // J. Crystal Growth, 2002, 23(9), P. 1773.

35. S. Iida, Y. Aoki, Y. Sugita et al. // Jpn. J. Appl. Phys., 2000, 39(11), P. 6130.

36. T. Ueki, M. Itsumi, T. Takeda // Jpn. J. Appl. Phys., 1999. 38(10), P. 5695.

37. Y.K. Kim, T.S. Ha, J.K. Yoon // J. Mater. Sci., 1998, 33(7), P. 4627.

38. V.T. Bublik, N.M. Zotov // Cryst. Rep., 1997, 42(6), P. 1147.

39. T. Ueki, M. Itsumi, T. Takeda et al. // Jpn. J. Appl. Phys., 1998, 37(7), P. L771.

40. M. Itsumi, M. Maeda, S. Ohfuji, T. Ueki // Jpn. J. Appl. Phys., 1999, 38(10), P. 5720. 